H. RENK ${ }^{1}$, J. NAKONIECZNY
, S. OCHOCKI
D. FICEK

\title{
SECCHI DEPTH-CHLOROPHYLL RELATIONSHIP IN THE BALTIC
}

\author{
Sea Fisheries Institute, Gdynia, Poland \\ and \\ 2Pedagogical College, Srupsk, Poland
}

\begin{abstract}
The paper presents data on Secchi depth in the Southern Baltic waters. The mean annual Secchi depth is $8.2 \mathrm{~m}$ in the Gdańsk Deep, $9.6 \mathrm{~m}$ in the Bornholm Deep, $9.9 \mathrm{~m}$ in the southern part of the Gotland Deep, and $5.7 \mathrm{~m}$ in the Gulf of Gdansk. The Secchi depth is subject to seasonal fluctuations, their amplitude being approximately $35 \%$ of the mean annual value. A trigonometric polynomial was applied to describe periodic intra-annual changes of Secchi depth in the Baltic. The largest water transparency was observed in winter, the transparency being lowest in summer. Effects of chlorophyll $a$ concentrations on water transparency are presented in a graphic form.
\end{abstract}

\section{INTRODUCTION}

Optical parameters of the environment are important factors in marine biological productivity studies. To investigate those parameters necessitates the use of modern and complex equipment. However, when making routine primary production measurements, it is not always possible to use such equipment. Hydrobiologists limit themsolves generally to a subjective evaluation of water transparency by means of the Secchi disc (Tyler 1968). The measurement involves determining a depth at which the Secchi disc is no longer visible. Knowledge of the Secchi depth may be useful for approximating mean coefficients of light attenuation by water (Graham 1966; Holmes 1970). It may also be useful when evaluating the so-called optical depth in primary production studies. 
MATERIALS AND METHODS

A white $30-\mathrm{cm}$ diameter Secchi disc was used. The data presented below were collected during cruises on board research vessels of the Sea Fisheries Institute in Gdynia and the Institute of Meteorology and Water Management in Gdynia within 1971-1986. Measurements of the depth at which the Secchi disc becomes invisible were auxiliary measurements during primary production studies. Positions of sampling sites are shown in Table 1.

\section{RESULTS AND DISCUSSION}

The depth at which the Secchi disc becomes invisible varies considerably and depends on the location; it also changes with time. In the Gdańsk Deep, the extreme values of the Secchi depth were $3 \mathrm{~m}$ in summer and $15 \mathrm{~m}$ in winter. In the Bornholm Deep and Gotland Deep, the largest depths at which the Secchi disc was still visible were 16 and $18 \mathrm{~m}$, respectively. Generally, a distinct seasonal periodicity was observed in the fluctuations of water transparency. Figs 1-4 show the results of Secchi depth measurements in the Gulf of Gdańsk (Puck Bay), Gdańsk Deep, Bronholm Deep, and the southern part of the Gotland Deep.

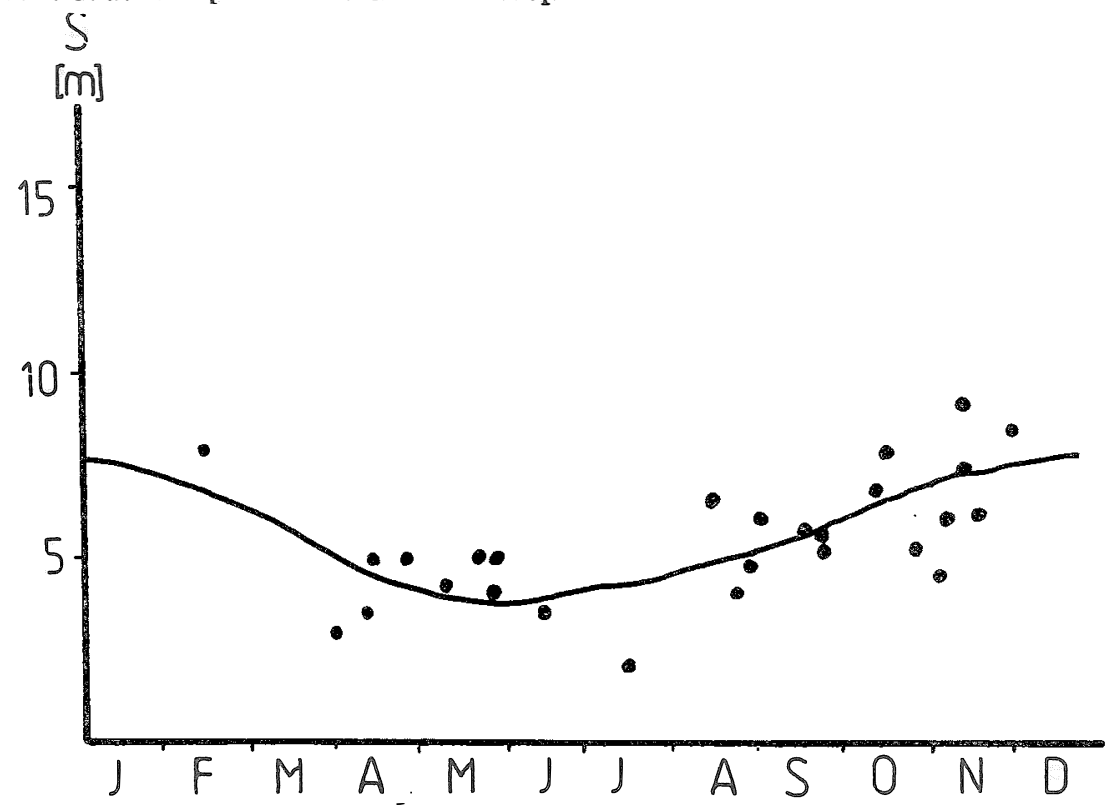

Fig. 1. Results of Secchi depth measurements in the Gulf of Gdańsk. The curve depicts averaged seasonal changes of Secchi depth as expressed with equation:

$$
S=5.69+1.78 \sin (\omega t+1.79)+0.29 \sin (2 \omega t+1.47)
$$




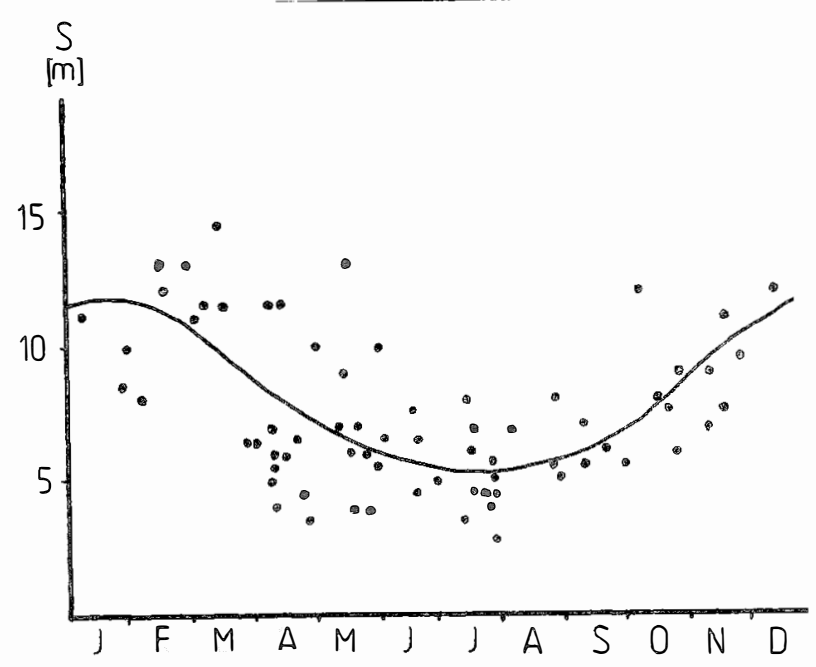

Fig. 2. Results of Secchi depth measurements in the Gdańsk Deep. The curve depicts averaged seasonal changes of Secchi depth, as expressed with equation:

$$
S=8.15+3.13 \sin (\omega t+1.26)+0.44 \sin (2 \omega t+1.33)
$$

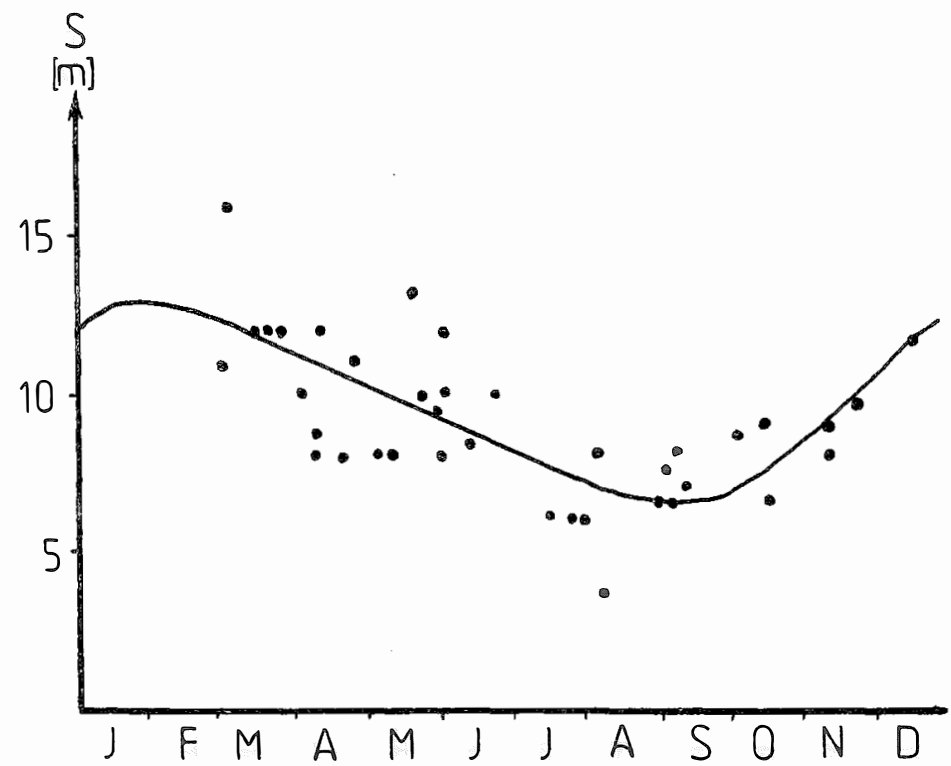

Fig. 3. Results of Secchi depth measurements in the Bornholm Deep. The curve depicts averaged seasonal changes of Secchi depth, as expressed with equation:

$$
S=9.64+2.98 \sin (\omega t+0.81)+0.64 \sin (2 \omega t+1.50)
$$




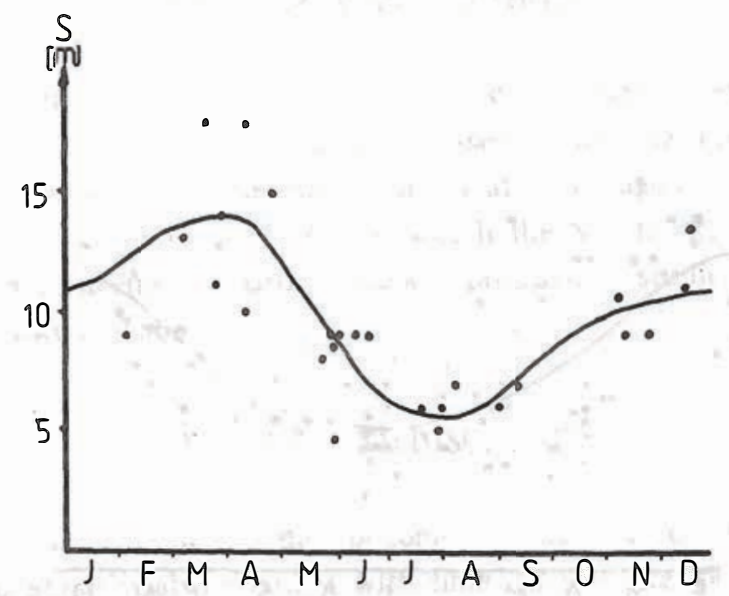

Fig. 4. Results of Secchi depth measurements 1e Gotland Deep. The curve depicts averaged seasonal changes of Secchi depth, as expressed with equation:

$S=9.86+3.42 \sin (\omega t+0.75)+1.45 \sin (2 \omega t+4.44)$

To describe seasonal changes of the Secchi depth, a trigonometric polynomial of the following type has been used:

$$
S=S_{0}+S_{1} \sin \left(\omega t+\varphi_{1}\right)+S_{2} \sin \left(2 \omega t+\varphi_{2}\right)
$$

where:

$$
\begin{aligned}
& S_{0}=\text { Secchi depth }(\mathrm{m}) \\
& S_{0}=\text { mean Secchi depth }(\mathrm{m}) \\
& S_{1}, S_{2}=\text { amplitudes of changes of } 1 \text { st and 2nd harmonic: } \\
& \omega \quad=\frac{2 \pi}{T} ; \\
& T \quad=365.25 \text { days. }
\end{aligned}
$$

Table 1

List of sampling stations

\begin{tabular}{|l|c|c|c|}
\hline \multirow{2}{*}{ Station } & & \multicolumn{2}{c|}{ Position } \\
\cline { 3 - 4 } & & Lat. & Long. \\
\hline Puck Bay & ZP & $54^{\circ} 37^{\circ}$ & $18^{\circ} 37^{\circ}$ \\
Puck Bay & $\mathrm{J}$ & $54^{\circ} 35^{\circ}$ & $18^{\circ} 45^{\circ}$ \\
Gdańsk Deep & $\mathrm{P}_{1}$ & $54^{\circ} 50^{\circ}$ & $19^{\circ} 20^{\circ}$ \\
Bornholm Deep & $\mathrm{P}_{5}$ & $55^{\circ} 15^{\circ}$ & $15^{\circ} 59^{\circ}$ \\
Gotland Deep & $\mathrm{P}_{40}$ & $55^{\circ} 38^{\circ}$ & $18^{\circ} 36^{\circ}$ \\
Puck Bay & $92 \mathrm{~A}$ & $54^{\circ} 37^{\circ}$ & $18^{\circ} 37^{\circ}$ \\
\hline Gulf of Gdańsk & $\mathrm{R}_{6}$ & $54^{\circ} 57^{\circ}$ & $18^{\circ} 25^{\circ}$ \\
\hline
\end{tabular}


Coefficients of equation: $S=S_{0}+S_{1} \sin \left(\omega t+\varphi_{1}\right)+S_{2} \sin \left(2 \omega t+\varphi_{2}\right)$

describing seasonal changes in Secchi depth

\begin{tabular}{|l|l|l|l|l|l|}
\hline \multicolumn{1}{|c|}{ Station } & $\mathrm{S}_{0}$ & $\mathrm{~S}_{1}$ & $\mathrm{~S}_{2}$ & $\varphi_{1}$ & $\varphi_{2}$ \\
\hline $\mathrm{J}, \mathrm{ZP}$ & 5.69 & 1.78 & 0.29 & 1.79 & 1.47 \\
$\mathrm{P}_{1}$ & 8.15 & 3.13 & 0.44 & 1.26 & 1.33 \\
$\mathrm{P}_{5}$ & 9.64 & 2.98 & 0.64 & 0.81 & 1.50 \\
$\mathrm{P}_{40}$ & 9.86 & 3.42 & 1.45 & 0.75 & 4.44 \\
\hline
\end{tabular}

Coefficients of Eq. 1 were calculated using the least squares method. A list of Eq. 1 coefficients is given in Table 2, while corresponding curves are plotted in Figs 1-4.

The mean Secchi depth in the Puck Bay was about $5.5 \mathrm{~m}$; it was about $8 \mathrm{~m}$ in the Gdańsk Deep (station P1) and over $9 \mathrm{~m}$ in the open waters of the southern Baltic. The amplitude of seasonal changes in the Secchi depth equals 30-40\% of the mean annual value. The lowest water transparency was observed during summer, i.e. at a time of a high biological activity.

Phytoplankton is one of the factors attenuating light in the sea. Figs 5 and 6 show the Secchi depth-mean chlorophyll concentration relationship in the southern Baltic. The curves in Figs 5 and 6 correspond to the equation:

$$
\frac{1}{S}=\mathrm{AChl}+\mathrm{B}
$$

where:

$S \quad=$ Secchi depth $(\mathrm{m})$

$\mathrm{Chl}=$ chlorophyll a concentration $\left(\mathrm{mg} / \mathrm{m}^{3}\right)$

$\mathrm{A}, \mathrm{B}=$ coefficients calculated with the least squares method.

The above equation shows the water transparency in the Baltic to be inversely proportional to chlorophyll concentration. Fig. 5 presents the Secchi depth-chlorophyll concentration relationship for three stations in the open waters of the southern Baltic in 1984, while Fig. 6 illustrates the corresponding relationship for the Puck Bay. Coefficients of Eq. 2, calculated with the least squares method, are presented in Table 3. Interannual and spatial differences in the coefficients are evident. A wide scatter of the data points in the figure may result from effects of other components of the water column (e.g. inorganic seston) on the transparency of the sea water. 


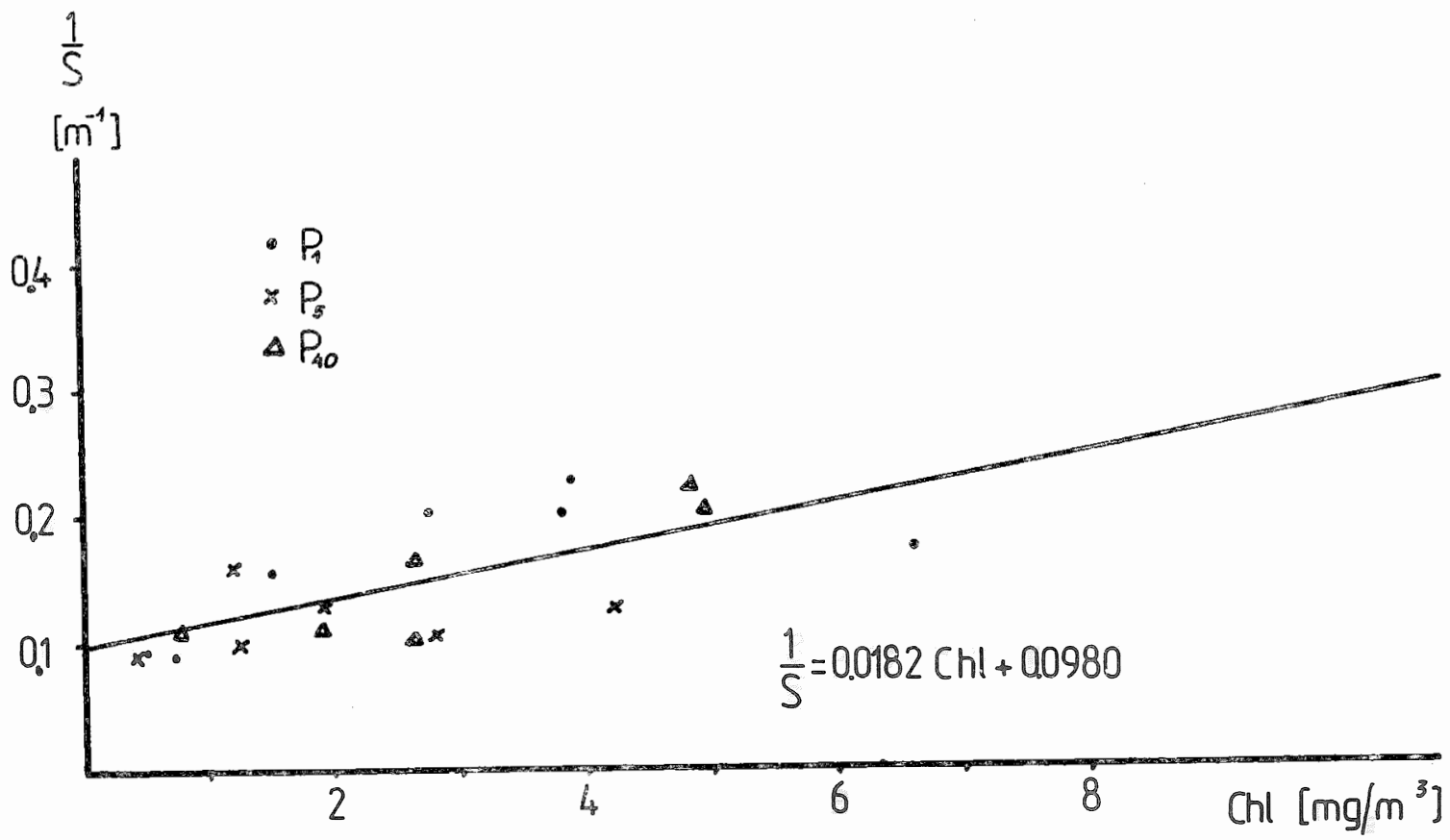

Fig. 5. Relationship between Secchi depth and chlorophyll - $a$ concentration in the Southern Baltic in 1984 


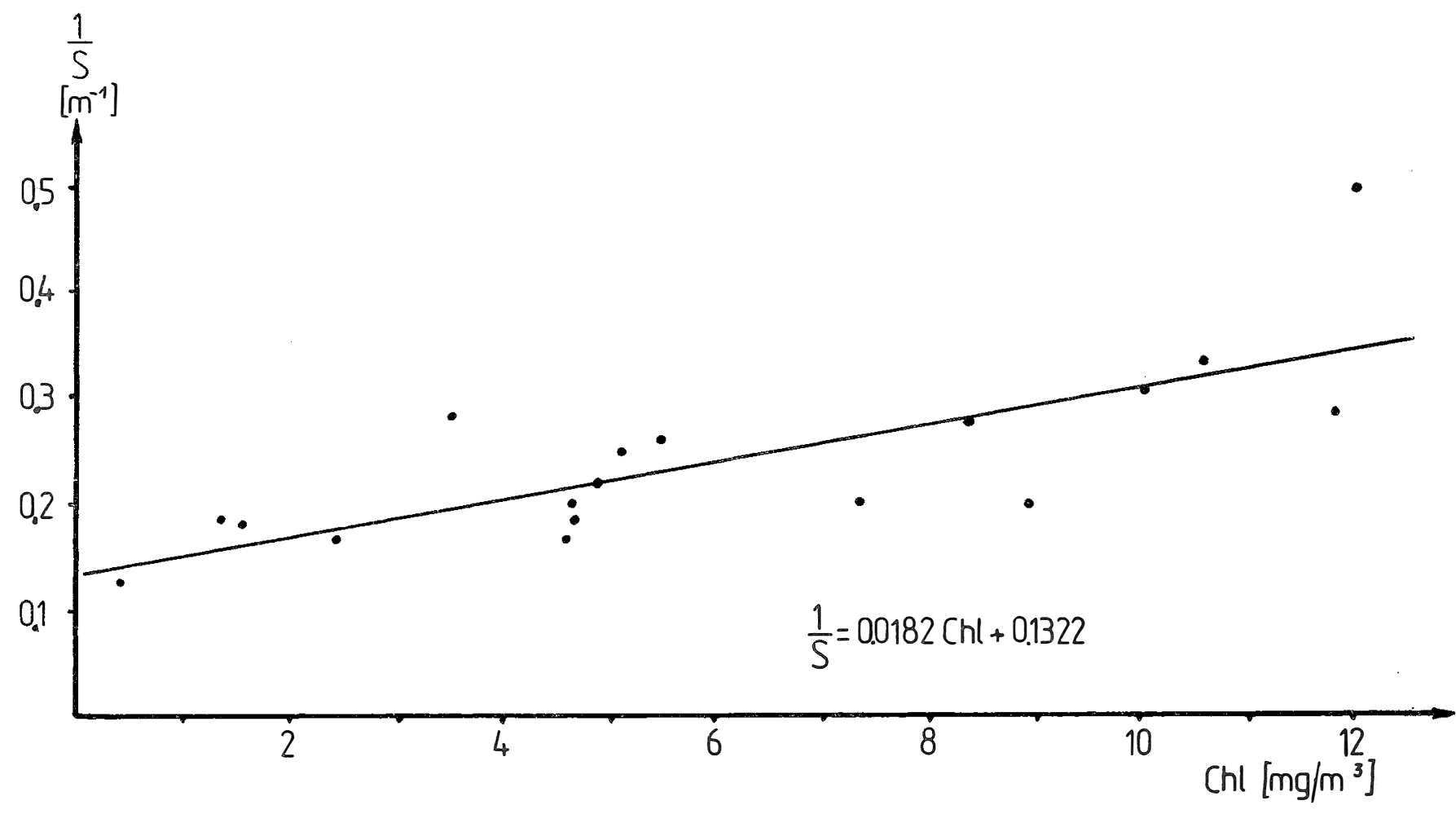

Fig.G. Relationship between Secchi depth and chlorophyll - $a$ concentration in Puck Bay in 1987 and 1988 
Table 3

Coefficients expressing relationship between Secchi depth and chlorophyll - a concentrations (Eq. 2)

\begin{tabular}{|c|c|c|c|c|c|}
\hline Station & Year & A & B & r & Sy \\
\hline$P_{1}, P_{5}, P_{40}$ & 1984 & 0.0182 & 0.0980 & 0.66 & 0.0366 \\
\hline$-"$ & 1985 & 0.0234 & 0.0761 & 0.58 & 0.0343 \\
\hline$-"-$ & 1986 & 0.0123 & 0.0953 & 0.51 & 0.0448 \\
\hline$-"$ & 1987 & 0.0197 & 0.1004 & 0.75 & 0.0471 \\
\hline $\mathrm{P}_{1}, \mathrm{P}_{5}, \mathrm{P}_{40}, \mathrm{R}_{6}, 92 \mathrm{~A}$ & 1988 & 0.0229 & 0.1091 & 0.75 & 0.0481 \\
\hline$P_{1}, P_{5}, P_{40}, R_{6}$ & 1987 & 0.0106 & 0.1193 & 0.41 & 0.0357 \\
\hline $\mathrm{P}_{1}, \mathrm{P}_{5}, \mathrm{P}_{40}, \mathrm{R}_{6}$ & 1988 & 0.0250 & 0.0959 & 0.69 & 0.0524 \\
\hline $\mathrm{R}_{6}, 92 \mathrm{~A}$ & 1987 & 0.0194 & 0.1174 & 0.77 & 0.0532 \\
\hline $\mathrm{R}_{6}, 92 \mathrm{~A}$ & 1988 & 0.0196 & 0.1399 & 0.87 & 0.0339 \\
\hline$R_{6}, 92 A$ & 1987, 88 & 0.0191 & 0.1241 & 0.77 & 0.0495 \\
\hline $92 \mathrm{~A}$ & 1987, 88 & 0.0182 & 0.1322 & 0.74 & 0.0603 \\
\hline $\mathrm{R}_{6}$ & 1987,88 & 0.0197 & 0.1197 & 0.59 & 0.0403 \\
\hline
\end{tabular}

\section{CONCLUSIONS}

1. Water transparency in the Baltic is subject to seasonal fluctuations. The largest transparency is observed in winter and the lowest in summer.

2. An effect of phytoplankton (chlorophyll concentration) on water transparency in the Baltic has been observed, although other components of the water column may also play a role here. 


\section{REFERENCES}

Graham J.J., 1966: Secchi disc observations and extinction coefficients in the central and eastern North Pacific Ocean. Limnol. Oceanogr., 11: 184-190.

Holmes R.W., 1970: The Secchi disc in turbid coastal waters. Limnol. Oceanogr., 15: 688-694.

Tyler J.E., 1968: The Secchi disc. Limnol. Oceanogr., 13: 1-6.

Author's addresses:

H. Renk, J. Nakonieczny, S. Ochocki, Z. Lorenz

Sea Fisheries Institute

Kołłątaja 1

81-345 Gdynia

Poland

R. Majchrowski, D. Ficek

Pedagogical College

Arciszewskiego 22

Słupsk

Poland 